In Wien nach Tribouillet's Verfahren dargestellte Fettsäuren bräunlich weiss aussehend, werden bei $39,5^{\circ}$ durchscheinend und schmelzen bei 48,30.

Andere kürzlich in Wien erzeugte Fettsäuren sind, wie die in Frankreich dargestellten rein weiss, und die Schmelzpuncte fallen mit denen der letzteren so ziemlich zusammen. (Sitzungsbr. der k. k. Akad. der Wissensch. zu Wien. Bd.12.)

$B$.

\title{
Darstellung der Benzoglycolsãure.
}

Nach Streckers Ansicht ist bekanntlich die Hippursäure als die Amidsäure der stickstoffireien Benzoglycolsäure $=\mathrm{C}^{18} \mathrm{H}^{8} \mathrm{O}^{8}=\mathrm{HO}+\mathrm{C}^{18} \mathrm{H}^{7} \mathrm{O}^{7}$ zu betrachten. Diese Säure nun stellte A. Gössmann aus der Hippursiiure folgendermaassen dar:

In ziemlich verdünnter überschüssiger Kalilauge löste er Hippursiiure auf' und leitete in der Kälte einen langsamen Strom von Chlorgas hinein in der Absicht, den durch Chlor verdrängten Saucrstoff, anstatt zu unterchlorigsaurem Kali, zunächst zur Zerstörung des Amids zu verwenden. Seine Vermuthung wurde bestätigt; es trat nämlich eine heftige Entwickelung von Stickgas ein. Sobald dieselbe beendet war, wurde die Chloreinleitung unterbrochen und mit Salzsäure nun die unterchlorige Säure sowohl ausgetrieben, als auch das überschüssige Alkali vorsichtig neutralisirt, hierauf die Flüssigkeit in gelinder Wärme concentrirt und mit verdünnter Salzsïure entschieden sauer gemacht. Hat man die Concentration gerade getroffen, so gesteht die ganze Lösung zu einem krystallinischen Brei von Benzoglycolsäure, wird sie dann noch einige Zeit warm gehalten, so scheidet sich ans einer solchen ïbersättigten Lösung diese Sïure in gelben ölartigen Tropfen ab, die beim Erkalten zu einer krystallinischen Masse erstarren, was charakteristisch ist. Durch gelindes $\Lambda$ bdunsten nach jedesmaliger Abstumpfung der freien Salzsäure lässt sich noch mehr Säure gewinnen.

Zur Reinigung löst man die Säure in Aether und giesst die Aetherlösung in ein Kölbchen über eine verhiiltnissmässig sehr geringe Wasserschicht und destillirt den Aether vorsichtig $a b$, in dem Maasse, als derselbe entweicht, sïttigt sich das Wasser und die überschüssige Säure scheirlet sich dann ölartig $\mathbf{a b}$ und ist frei von Hippursäure und Benzöesäure. Berücksichtigt man die 
196 Fabrikation Alicht. Kohlenoaser'stoffe u. des Paraffins.

Theoric des Vorganges und die Eigenthümlichkeiten der Benzoglylcolsäure, so ergeben sich dic Regeln für die Leitung der Operation von selbst $d$. h. es muss stets ein Ueberschuss von Alkali beim Finleiten des Chlors vorhanden sein, die Mischung während der Operation möglichst kühl erhalten werden und endlich beim Concentriren so viel als thunlich ein Ueberschuss von Mineralsäuren vermieden werden. Lïsst man Chlor in Ueberschuss einwirken, so scheidet sich innerhalb 24 Stunden, oft noch früher, ein gelber, ölartiger, anscheinend fortwïhrend in Zersetzung begriffener Körper aus, der wahrscheinlich ein gechlortes Product der Benzoësäure ist.

Bei der Leichtigkeit, mit der diese Darstellungsweise der Benzoglycolsäure auszuführen ist, scheint das eingeschlagene Verfahren auch auf die Zerlegung anderer Amidsäuren ausgedehnt werden zu können. (Aunal. der Chem. u. Pharm. XIV. 181-184.)

$G$.

\section{Veber Fabrikation der flüchtigen Kohleuwasserstofle und des Paraffins.}

Das dem Ingenieur Wangemann in Bonn patentirtc Verfahren der Bereitung von Paraffin etc. besteht darin, dass man die Kohlen oder bituminösen Schiefer, dic als Material dienen, zu wallnussgrossen Stiicken zerkleinert, und im Fall sie Schwefel enthalten, mit Kalkwasser besprengt.

Dieses Material wird in zweckmässig eingerichteten Räumen getrocknet, auf gemauerten Gewölben, unter welche die bei der Jestillation rückstïndig bleibende glühende Asche als Heizmaterial gebracht wird. Der Erfinder legt Oefen von 8 Feuern mit 16 Retorten rund herum um ein Kamin, wobei die Flamme von einem Feuer zum andern geführt werden kann und die Retorten einer zunehmenden Hitze ausgesetzt sind. Die Destillationsproducte zichen alls den Retorten, von den Finden derselben, die dem Roste entgregengesetat sind, durch ein eisernes Rohr von 80 Fuss Länge und 2 Fuss Durchmesser ab. Dieses ist von aussen stets mit kaltem Wasser umgeben. Von hieraus treten die Gase in grosso eiserne Cylinder, die mit Koaks gefuillt sind, welche ihnen die letzten Theerantheile entzichen. Von hieraus gelan. gen die Gase in cinen 40 Fuss hohen Kamin, dessen Zug durch einen Regulator adjustirt wird. 